\title{
Cardiac rhabdomyomas and their association with tuberous sclerosis
}

\author{
David W Webb, R D Thomas, John P Osborne
}

\begin{abstract}
A search for children presenting with signs or symptoms of cardiac rhabdomyomas was made through members of the paediatric section of the British Cardiac Society in order to establish their birth incidence, presenting features, clinical course, and the frequency of a concurrent diagnosis of tuberous sclerosis. Fifteen children were identified and 12 had tuberous sclerosis $(\mathbf{8 0} \%)$. Heart failure was the presentation in six, five of whom died; six presented because of a murmur and three because of arrhythmias. The prevalence of echocardiographic evidence of cardiac rhabdomyomas in a population of patients with tuberous sclerosis was established. Twenty individuals had echocardiography and eight had echodensities consistent with cardiac rhabdomyomas.

It is concluded that the minimum birth incidence for children presenting because of the effects of cardiac rhabdomyomas is $1 / 326000$ and a minimum of $80 \%$ have tuberous sclerosis. In a population of patients with tuberous sclerosis a minimum of $60 \%$ under 18 years have cardiac rhabdomyomas.

(Arch Dis Child 1993; 68: 367-370)
\end{abstract}

Symptomatic primary heart tumours are rare in childhood. In several reviews cardiac rhabdomyomas have been the commonest lesion. ${ }^{1-4}$ Until recently these hamartomas were usually diagnosed at necropsy but with improved noninvasive imaging they are now diagnosed with reasonable certainty in infancy and childhood. Their natural history is still unclear.

They represent the earliest detectable hamartoma in tuberous sclerosis where they have been diagnosed in fetal life as early as 22 weeks' gestation. As they may be the only manifestation of tuberous sclerosis at this stage the probability that other features of the disease will develop with time is important for genetic counselling and patient management. A review of all published cases of cardiac rhabdomyomas up to 1990 found at least $50 \%$ to be associated with tuberous sclerosis. ${ }^{5}$ However the majority of cases reported are in young infants when excluding a diagnosis of tuberous sclerosis can be extremely difficult even at postmortem examination. ${ }^{6} \mathrm{~A}$ nationwide search for children presenting with symptoms and signs due to cardiac rhabdomyomas could give some indication of their minimum birth incidence and with improved survival and more widespread use of modern imaging techniques might also give a more accurate estimate of their true association with tuberous sclerosis.

Estimates of the frequency of cardiac rhabdo- myomas in patients with tuberous sclerosis have been made ${ }^{7-10}$ but an estimate of their prevalence in a population based study has not previously been reported.

\section{Methods}

Members of the paediatric section of the British Cardiac Society were asked to identify infants that they had seen presenting because of the effects of cardiac rhabdomyomas. Case histories were reviewed and where possible contact with the family was made to assess recent progress. Individuals with tuberous sclerosis resident in the Bath health district were identified by a large prevalence study ${ }^{11}$ and were offered transthoracic cross sectional echocardiography. This was performed by a consultant cardiologist (RDT) on an ATL Ultramark 9 machine with a $3 \mathrm{MHz}$ phased array scanner. Two dimensional examinations were made from parasternal, subcostal, and apical windows and the images recorded on videotape. Echodensities greater than $5 \mathrm{~mm}$ in greatest diameter that were discreet and clearly more echodense than the adjoining myocardium were considered significant.

\section{Results}

Seventy five per cent of cardiologists replied to the search, including members from all the supraregional centres in England and regional centres in Scotland. Fifteen cases (10 boys, five girls) were identified with presentation due to cardiac rhabdomyomas. Five individuals were diagnosed in utero after routine ultrasound. One was hydropic and died. After birth the remaining four each had a murmur. Of those found in the neonatal period, five had heart failure, four of whom died, while two presented because of a murmur and one because of an arrhythmia. The two postneonatal presentations were with arrhythmias (table 1). Of the five infants who died, two had left ventricular outflow tract obstruction and three had huge intramural tumours involving most of the left ventricle. The clinical features at presentation are shown in table 2. Arrhythmias were common but were less frequently the presenting feature. Three infants

Table 1 Reason for presentation in 15 children with cardiac rhabdomyomas

\begin{tabular}{lll}
\hline $\begin{array}{l}\text { Antenatal diagnosis } \\
(n=5)\end{array}$ & $\begin{array}{l}\text { Neonatal } \\
(n=8)\end{array}$ & $\begin{array}{l}\text { Postneonatal } \\
(n=2)\end{array}$ \\
\hline $\begin{array}{l}\text { Hydrops (1) } \\
\text { Murmur (4) }\end{array}$ & $\begin{array}{l}\text { Heart failure (5) } \\
\text { Murmur (2) } \\
\text { Arrhythmias (1) }\end{array}$ & Arrhythmias (2) \\
\hline
\end{tabular}

${ }^{\star}$ Diagnosis was made at routine antenatal ultrasound; features given are those present at birth. 
Table 2 Clinical features, outcome, and concomitant diagnosis of tuberous sclerosis in 15 children presenting because of the effects of cardiac rhabdomyomas

\begin{tabular}{|c|c|c|c|c|c|c|c|}
\hline Age & Sex & Murmur & Cyanosis & Failure & Arrhythmia & $\begin{array}{l}\text { Tuberous } \\
\text { sclerosis }\end{array}$ & Outcomet \\
\hline \multicolumn{8}{|c|}{ Detected antenatally (weeks): } \\
\hline 24 & $M^{\star}$ & + & - & - & - & + & 4 years \\
\hline 31 & $\mathrm{M}$ & - & + & + & - & + & Died on day 1 \\
\hline 32 & $M$ & + & - & - & + & + & 9 months \\
\hline 33 & $M$ & + & - & - & Atrial ectopics/ventricular ectopics & + & 9 months \\
\hline 39 & $\mathbf{F}$ & + & + & - & - & + & 3 years \\
\hline \multicolumn{8}{|c|}{ Days after birth: } \\
\hline 1 & $M$ & + & + & + & Atrial ectopics/sinus bradycardia & + & Died on day 2 \\
\hline i & $M$ & - & - & + & - & + & Died on day 11 \\
\hline 1 & $\mathbf{F}$ & + & - & - & - & + & 14 months \\
\hline l & $\mathbf{F}$ & + & + & - & - & ? & 3 years \\
\hline 1 & $F^{\star}$ & - & + & + & Ventricular fibrillation/sinus bradycardia & ? & Died on day 1 \\
\hline 2 & $M$ & - & - & - & Supraventricular tachycardia/WPW & ? & 6.5 years \\
\hline 8 & $\mathrm{~F}$ & + & - & + & - & + & 4 years \\
\hline 9 & M & + & + & + & WPW & + & Died on day 30 \\
\hline \multicolumn{8}{|c|}{ Months after birth: } \\
\hline 2 & $M$ & - & - & - & Supraventricular tachycardia/WPW & + & 10 years \\
\hline 10 & $M$ & - & + & - & Supraventricular tachycardia & + & 3.5 years \\
\hline
\end{tabular}

*Single lesion. $\nmid$ Age at which still alive or age at death. WPW $=$ Wolff-Parkinson-White syndrome; $+=$ present, $-=$ absent .

had Wolff-Parkinson-White syndrome. Twelve had tuberous sclerosis: eight were sporadic and the four familial cases were the family proband. All of the children with tuberous sclerosis who survived developed seizures and two are reported to be developing normally at 3.5 and 4 years. The remainder have some degree of mental retardation. The three cases in whom a diagnosis of tuberous sclerosis was not established were a newborn girl with a single rhabdomyoma who had no evidence of tuberous sclerosis at postmortem examination, a 6 year old boy who had not been specifically investigated for evidence of tuberous sclerosis, and a 3.5 year old girl who had normal cranial and renal ultrasound in infancy.

Tumours were multiple in $13(87 \%)$ and involved the left ventricle in $11(73 \%)$, right ventricle in 11 , interventricular septa in eight $(54 \%)$, and atria in two (13\%). The diagnosis was confirmed histologically in seven cases. Three individuals had surgery, two for removal of lesions obstructing the right ventricular outflow tract and one for involvement of the mitral valve which required replacement. No lesions increased in size and at follow up in five children significant reduction in tumour size had been documented.

Twenty three individuals with tuberous sclerosis resident in the Bath health district were identified by a prevalence study." Twenty con-

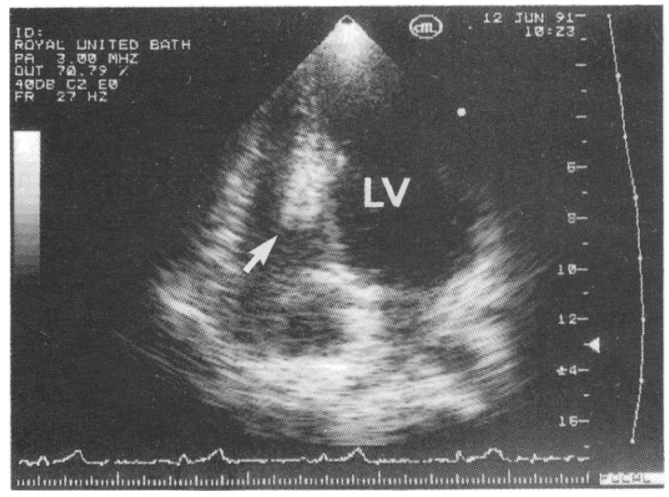

Figure 1 Subcostal four chamber view showing a large septal lesion extending into the right ventricle in a 39 year old woman with tuberous sclerosis. $L V=$ left ventricle. sented to echocardiography (10 male and 10 female) and eight had echodense areas consistent with cardiac rhabdomyomas (see table 3 ). Six of 10 individuals who were 18 years or under had abnormal echodensities. One women with a large interventricular septal lesion (fig 1) gave a history of palpitations and the remaining patients were asymptomatic. One newborn boy whose mother has tuberous sclerosis had multiple echodensities when scanned at 2 days of age. He was clinically normal and had normal cranial ultrasound. A repeat echocardiogram at 6 weeks of age was normal on multiple views (fig 2). He has since developed seizures at 19 months of age and has cerebral tubers on magnetic resonance imaging.

\section{Discussion}

Tuberous sclerosis is an important cause of fits and mental handicap with a birth incidence of about 1/6000." Mental handicap occurs only in patients with early onset of seizures. Identifying lesions that have a high association with the disease has important implications for patient management, including the avoidance of factors that might precipitate seizures, early recognition, and treatment of seizures and genetic counselling.

We have identified 15 infants presenting because of cardiac rhabdomyomas and tried to establish the number that turned out to have tuberous sclerosis. Six other infants with presentation due to cardiac rhabdomyomas have been reported in England from 1981-90. ${ }^{12-1+}$ The total live births for England and Scotland for the same period was 6851488 (Office of Population Censuses and Surveys, 1990) and the minimum birth incidence is therefore $1 / 326000$. The birth incidence of asymptomatic lesions will be considerably higher as a high percentage of children with tuberous sclerosis have abnormal echodensities when scanned (table 3 ).

The majority of cardiac rhabdomyomas are now diagnosed by echocardiography. This assumes a good correlation between the images found and the histological lesion and this has now been established in a newborn infant. '" In addition the other primary heart tumours at this age (teratomas, myxomas, and fibromas) are significantly different both clinically and ultra- 

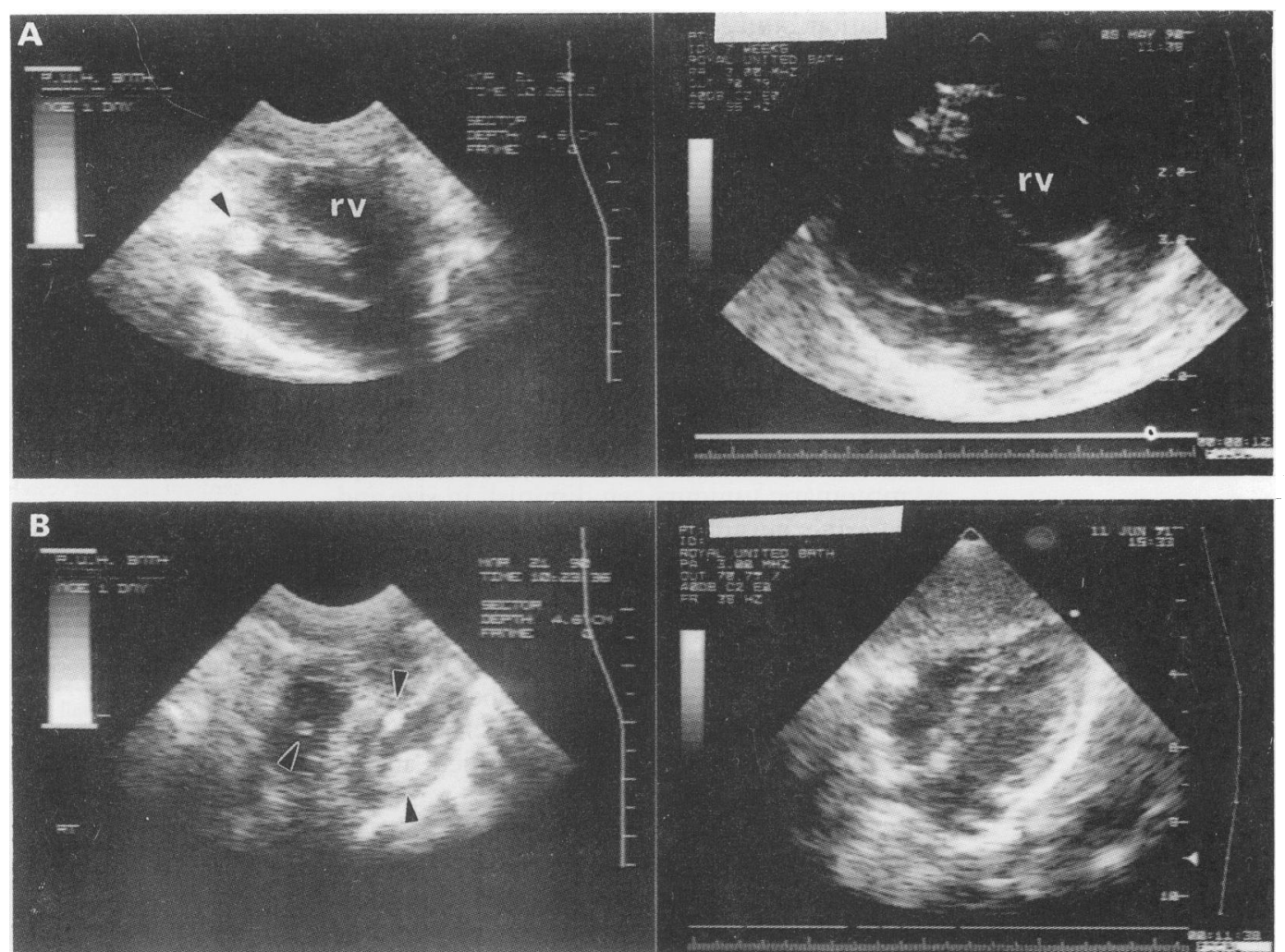

Figure 2 (A) Long axis parasternal views taken on day 1 (left) and at 6 weeks of age (right) in an infant whose mother had tuberous sclerosis. An echodense lesion is seen at the apex of the left ventricle which disappears on the second view. (B) A four chamber view of the same infant shows multiple echodensities (left) that have resolved at 6 weeks of age (right).

sonically. While most rhabdomyomas are multiple, even a single lesion in infancy is very likely to be a rhabdomyoma and if other features of tuberous sclerosis are found the diagnosis is beyond reasonable doubt.

Infants with cardiac rhabdomyomas present with features related to the size and anatomical location of their tumour. Large obstructive lesions and those interfering with cardiac motility have a poor prognosis. In this study five of six cases presenting in cardiac failure died and all six had large left ventricular lesions. The surviving child is now 4 years old and asymptomatic but did require a period of ventilatory support at 2 weeks of age and had mitral valve replacement at 18 months for a lesion involving the valve. Three infants presented with symptoms related to supraventricular tachycardia and two of these had Wolff-Parkinson-White syndrome. Neonatal or fetal arrhythmias should alert the clinician to the possibility of a cardiac

Table 3 Abnormal echocardiographic findings in eight patients from a population of 20 patients with tuberous sclerosis. There were no atrial lesions seen

\begin{tabular}{llllll}
\hline & & \multicolumn{4}{l}{ Site and size $(\mathrm{mm})$} \\
\cline { 4 - 6 } Age & Sex & $\begin{array}{l}\text { Noof } \\
\text { areas }\end{array}$ & $\begin{array}{l}\text { Left } \\
\text { ventricle }\end{array}$ & $\begin{array}{l}\text { Right } \\
\text { ventricle }\end{array}$ & $\begin{array}{l}\text { Interventricular } \\
\text { septum }\end{array}$ \\
\hline 1 day & $M^{\star}$ & 3 & 14 & 8 & 8 \\
2.5 years & $M^{\star}$ & 1 & & & 8 \\
4 years & $M$ & 1 & 6 & & 8 \\
16 years & $M$ & 2 & 19 & & \\
18 years & $M$ & 1 & 9 & 10 & \\
46 years & $M$ & 1 & & 12 & 42 \\
9 years & F & 1 & & & \\
39 years & F & 2 & 23 & & \\
\hline
\end{tabular}

^Spontaneous and complete resolution documented. tumour. Lesions presenting with an asymptomatic neonatal murmur are those most likely to be missed. There were two infants identified who presented in this way and another who presented with a supraventricular tachycardia and WolffParkinson-White syndrome, who were only diagnosed as having cardiac rhabdomyomas after they developed seizures and were found to have tuberous sclerosis. For this reason they have not been included in the analysis.

It has been difficult to establish the true relationship between tuberous sclerosis and this hamartoma. Early death, inadequate follow up, or incomplete evaluation may result in failure to diagnose tuberous sclerosis. In this study an association could not be confirmed in three cases. Two of these have not been completely investigated. The third case died on day one and had an otherwise normal postmortem examination including normal brain histology. Interestingly another infant with no clinical evidence of the disease and with normal brain histology had a mother and grandfather with tuberous sclerosis confirming the diagnosis. ${ }^{15}$ Several other cases highlight diagnostic pitfalls. Woods lamp examination was normal at 1 month in an infant who was later discovered to have multiple hypomelanic macules. Another infant without hypomelanic macules has developed a shagreen patch at 19 months. The external surface of the cerebral hemispheres appeared normal in one infant who had complete malformation of several gyri with cortical tubers on histological examination.

The prevalence of cardiac rhabdomyomas in patients with tuberous sclerosis has been estimated from hospital based samples. This 
population study found $60 \%$ of such children and $20 \%$ of such adults to have echocardiographic evidence of tumours and the prevalence for the whole group is $40 \%$. These figures support the work of Smith et al who found tumours in $58 \%$ of children and $18 \%$ of adults who had attended clinical genetic or paediatric neurology outpatient departments. ${ }^{9}$ We would also agree with the difficulty in interpretation of small reflectile areas and bulky papillary muscles, particularly in adults. ${ }^{16}$

Our study suggests that the birth incidence for cardiac rhabdomyomas in patients with tuberous sclerosis is likely to be higher than $60 \%$ as asymptomatic tumours can diminish in size and disappear echocardiographically within weeks of birth. This potential for spontaneous regression has been noted by several authors before but not to such a dramatic degree in such a short time..$^{1718}$ It is likely that an increasing number of cardiac rhabdomyomas are going to be diagnosed antenatally. This lesion has never been shown to grow postnatally and it may be justified, in the light of our findings, to consider premature induction of labour in a fetus developing signs of cardiac failure because of a cardiac rhabdomyoma. While most rhabdomyomas appear to regress spontaneously, some infants may benefit from surgery for obstructive lesions and this should be considered at an early stage. The prevalence of mental handicap in an unbiased sample of tuberous sclerosis patients is only $38 \%^{19}$ so despite a likely diagnosis of tuberous sclerosis in children presenting because of the effects of cardiac rhabdomyomas the long term outlook is that they are more often intellectually normal than not.

This paper was only made possible with the help of the following physicians who kindly responded to our search for cases: Dr L Allan, London; Dr N Archer, Oxford; Dr J Burns, Edinburgh Professor R Cooke and Dr I Peart, Liverpool; Dr J De Giovani, Birmingham; Dr L Fong and Dr B Keeton, Southampton; Dr A Houston, Glasgow; Dr S Jordan, Bristol; Dr R Leanage, Leicester; Dr A Reddington and Dr E Shinebourne, London;
Dr N Rutter, Nottingham; and Dr S Hodges and Dr C Wren, Newcastle upon Tyne.

Dr David Webb is supported by a grant from the Tuberous Sclerosis Association and by the Bath Unit for Research into Paediatrics. We would like to thank Cow and Gate Ltd, Glaxo Laboratories Ltd and Avon Rubber plc for their financial support. We would also like to thank the physicians who kindly provided We would also like to thank the physicians who kindly provided the clinical details and the patients and their guardians who gave of
their time.

1 Van der Hauwaert LG. Cardiac tumours in infancy and childhood. Br Heart f 1971; 33: 125-32.

2 Simcha A, Wells BG, Tynan MJ, Waterson DJ. Primary cardiac tumours in childhood. Arch Dis Child 1971; 46: 50814.

3 McAllister HA Jr. Primary tumours of the heart and pericardium. Pathol Annu 1979; 14: 325-55.

4 Chan HS, Sonley MJ, Frederic CA, et al. Primary and secondary tumours of childhood involving the heart, pericardium and great vessels. Cancer 1985; 56: 825-36.

5 Harding CO, Pagon RA. Incidence of tuberous sclerosis in patients with cardiac rhabdomyomas. Am F Med Genet 1990; 37: 443-6.

6 Webb DW, Osborne JP. Incidence of tuberous sclerosis in patients with cardiac rhabdomyomas. Am F Med Genet 1992; 42: 754 .

7 Gibbs JL. The heart and tuberous sclerosis, an echocardiographic and electrocardiographic study. Br Heart $\mathcal{F}$ 1985; 54 :

8 Bass JL, Breningstall GN, Swaiman KF. Echocardiographic incidence of cardiac rhabdomyoma in tuberous sclerosis. Am $\mathrm{F}$ Cardiol 1985; 55: 1379-82.

9 Smith HC, Watson GH, Patel RG, Super M. Cardiac rhabdomyomata in tuberous sclerosis: their course and diagnostic myomata in tuberous sclerosis: their cours
value. Arch Dis Child 1989; 64: 196-200.

value. Arch Dis Child 1989; 64: 196-200.
10 Manetti A, De Simone L, Favilli S, et al. Studio ecocardiografico del rabdomioma cardiaco nella sclerosi tuberosa. G Ital Cardiol 1989; 19: 319-23.

11 Osborne JP, Fryer AE, Webb DW. Epidemiology of tuberous sclerosis. Ann NY Acad Sci 1991; 615: 125-7.

12 Allan LD, Joseph MC, Tynan M. Clinical value of echocardiographic colour image processing in two cases of primary cardiac tumour. Br Heart $\mathcal{F} 1983 ; 49$ : $15+6$.

13 Thompson N, Read K. Multiple rhabdomyoma in a neonate: case report. Radiography 1987; 52: 75-7.

14 Wallace G, Smith HC, Watson GH, et al. Tuberous sclerosis presenting with fetal and neonatal cardiac tumours. Arch Dis Child 1990; 65: 377-9.

15 Osborne JP. Diagnosis of tuberous sclerosis. Arch Dis Child 1988; 63: 1423-5.

16 Webb DW, Thomas RD, Osborne JP. Echocardiography for genetic counselling in tuberous sclerosis. $\mathcal{F}$ Med Genet 1992; 29: 487-9.

17 Smythe JF, Dyck JD, Smallhorn JF, Freedom R.M. Natural history of cardiac rhabdomyoma in infancy and childhood. Am $\mathcal{F}$ Cardiol 1990; 66: 1247-9.

18 Alkalay AL, Ferry DA, Lin B, et al. Spontaneous regression of cardiac rhabdomyoma in tuberous sclerosis. Clin Pediatr (Phila) 1987; 26: 532-4

19 Webb DW, Osborne JP, Fryer AE. On the incidence of fits and mental retardation in tuberous sclerosis. $\mathcal{F}$ Med Genet 1991; 28: 395-7. 